\title{
Study on Integrated Control Technology of High Ground Stress in Low Gassy Fully Mechanized Working Face
}

\author{
Zunyu $\mathrm{Xu}^{1,2}$ \&Benqing Yuan ${ }^{1,2}$ \&Yongjiang Zhang ${ }^{1,2}$ \\ 1. National Key Laboratory of Gas Disaster Detecting, Preventing and Emergency Controlling \\ 2. China Coal Technology Engineering Group Chongqing Research Institute, Chongqing, china
}

\begin{abstract}
KEYWORD: High ground stress;Dynamic disaster;Gas pre drainage;Deep water injection ABSTRACT: Through analyzing the dynamic disasters of KuZiDong mine 111303 working face in this paper,aiming at the high stress and low gas working face,that ucsing Composite regional measures of "the gas pre drainage standard before mining and effectively reducing the coal seam rockburst tendency through water injection" was proposed.That proving the" gas pre drainage + deep water injection" is a method of dynamic disaster prevention of coal gas most effectively. There is reference to mine deep mining dynamic disaster(including coal and gas outburst, rock burst) control.
\end{abstract}

\section{Introduction}

Coal and gas outburst, rock burst is the two typical coal and rock dynamic disasters, domestic and foreign has carried out a lot of research, and achieved remarkable results. With the increase of mining depth and intensity, deep mining showing a high force, high gas pressure and high temperature phenomenon, under the environment of coal and rock mass mechanical characteristics have don't in the shallow coal and rock mass mechanics characteristic, such as surrounding rock stress field evolution of complex, large deformations of surrounding rocks and strong rheological, coal and rock brittle ductile transition, dynamic response of sudden change, in deep mine coal and gas outburst governance challenge. Therefore, it is a need to break through the traditional coal and gas outburst, and the impact of some understanding and concept of the coal mine.

\section{GENERAL SITUATION}

The first mining depth of nearly $1000 \mathrm{~m}$, and high stress, high temperature and other hazards in SDIC Xinji Fuyang Mining Co., Ltd. Kou Zi Dong Kuang (referred to as KuZiDong mine)。A main entry in shaft station repair depth reached $5700 \mathrm{~mm}$ within 3 years , and the first mining area $13-1$ coal seam temperature run up to 38.8 degrees. The 13-1 coal seam in central area of mine one level was identified as non outburst coal seam, which has the risk of rock burst. The 111303 working face is the first mining face of the coal mine, $1975 \mathrm{~m}$ long, 328m inclined width, the avege thickness of $4.6 \mathrm{~m}$, the average angle of 11 degrees, using the comprehensive mechanized coal mining method, once mining full height mining intensity. The process of mining coal sudden extrusion or impact dynamic risk in geological tectonic belt or mining stress concentration area, which can cause the general dynamic damage characteristics, but also may cause the work surface air gas overrun and other hazards. This kind of disaster energy is mainly from top and bottom slate layer and hard coal seam containing the elastic energy released suddenly,it is difficult to use regional measures of borehole pre pumping gas to eliminate the danger ${ }^{[1]}$.

\section{ANALYSIS OF HIGH STRESS AND LOW GAS DYNAMIC DISASTER}

111303 working face west from the 13-1 coal seam in the coal pillar line, East from F13 fault protection coal pillar line, North to 111305 design working surface, South of 111301 working face design, the working face as a whole to nearly EW.The 111303 working face mining elevation is -709m $864 \mathrm{~m}$, The working face is flat as shown in figure 1. The direct roof of 13-1 coal seam is composed of mudstone, sandy mudstone and coal line, and the bottom is mainly mudstone. The working face of coal seam measured maximum gas pressure is $0.38 \mathrm{MPa}$, the gas initial velocity is $9 \sim 10$, protodyakonov coefficient is $0.5 \sim 0.94$, damage type of coal is $\mathrm{I} \sim \mathrm{II}$, local $5 \sim 10 \mathrm{~cm}$ is thick soft layer, the gas content is $5.38 \sim 5.44 \mathrm{~m}^{3} / \mathrm{t}$. The $13-1$ coal seam and its roof strata are strong impact tendency. 
From the gas, geological and engineering factors and stress concentration analysis, application level analysis method analysis $111303^{[1]}$ shows that there are dynamic disaster risk region has five blocks (as shown in Figure 1).

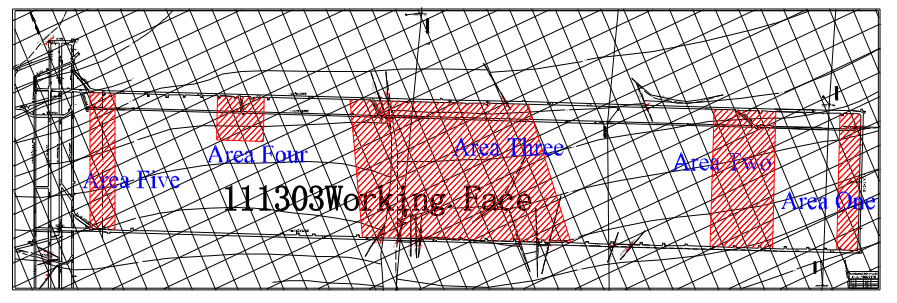

Figure.1 111303 working face layout plan

\section{PREVENTION AND CONTROL MEASURES OF HIGH STRESS AND LOW GAS DY- NAMIC DISASTER}

The 111303 working face mining process was in the presence of stress as the leading coal gas power disaster,and take the first area, comprehensive prevention and control of local coal gas dynamic disasters measures.In the 111303 working face, the composite regional measures are mainly adopted for the "pre pumping gas pre pumping standard and the water injection to reduce the impact of the coal seam". The process of mining gas emission according to source control,the main use of the bedding pre - mining, while mining side pumping, High drainage roadway drainage , enhanced ventilation and other methods to prevent gas concentration overrun ${ }^{[2]}$.

The 111303 working face day output is 10000 14000t,According to"Prediction method of mine gas emission quantity"predict the relative gas emission rate of 111303 fully mechanized coal face $3.41 \mathrm{~m}^{3} / \mathrm{t}$, The absolute gas emission quantity of the working face is $23.68 \sim 33.15 \mathrm{~m}^{3} / \mathrm{min}$, and the air quantity of the 111303 mechanized coal face is $2200 \sim 3200 \mathrm{~m}^{3} / \mathrm{min}$.

\section{CONTROL EFFECT OF HIGH STRESS AND LOW GAS DYNAMIC DISASTER}

\section{Analysis of gas drainage in coal seam}

The change curve of bedding drilling, high pumping lane and wind gas displacement in 111303 working face is in figure 2 5,pump displacement is shown in table 1.

From figure 2 5 and table 1, the overall effect of mining gas drainage is as follows:

(1) When the working face mining distance is $1247 \mathrm{~m}$, the gas drainage quantity is 18187000 $\mathrm{m}^{3}$,Among them:bedding borehole gas drainage was $3353700 \mathrm{~m}^{3}$, high pumping Lane pure gas drainage volume was $9416400 \mathrm{~m}^{3}$, pure wind gas volume was $5416900 \mathrm{~m}^{3}$, and gas drainage effect is obvious.

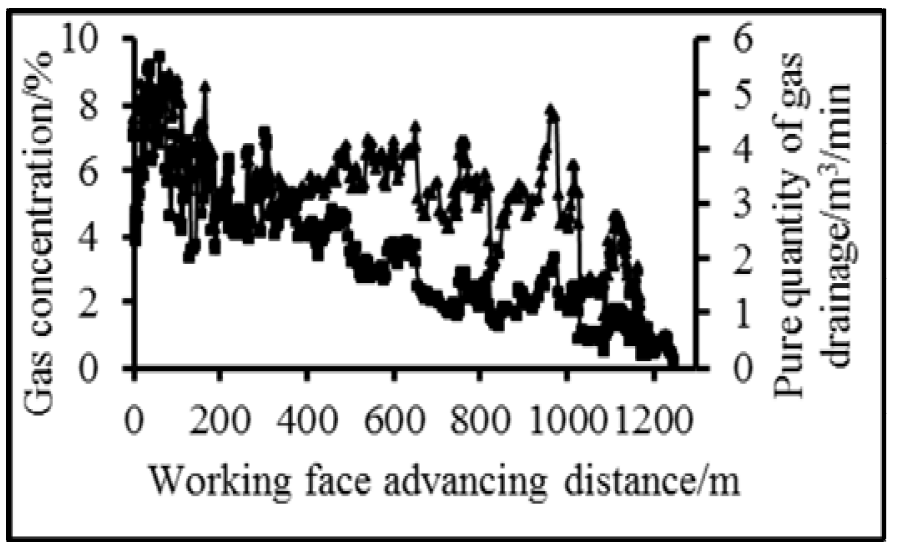

Figure. 2 The curve of gas concentration and purity for the 111303 working face machine roadway bedding drilling 


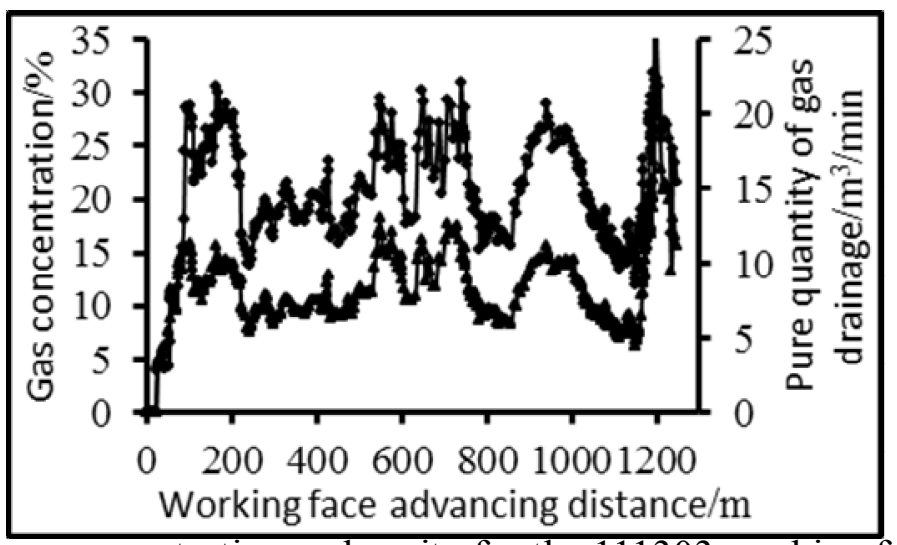

Figure. 3 The curve of gas concentration and purity for the 111303 working face wind roadway bedding drilling

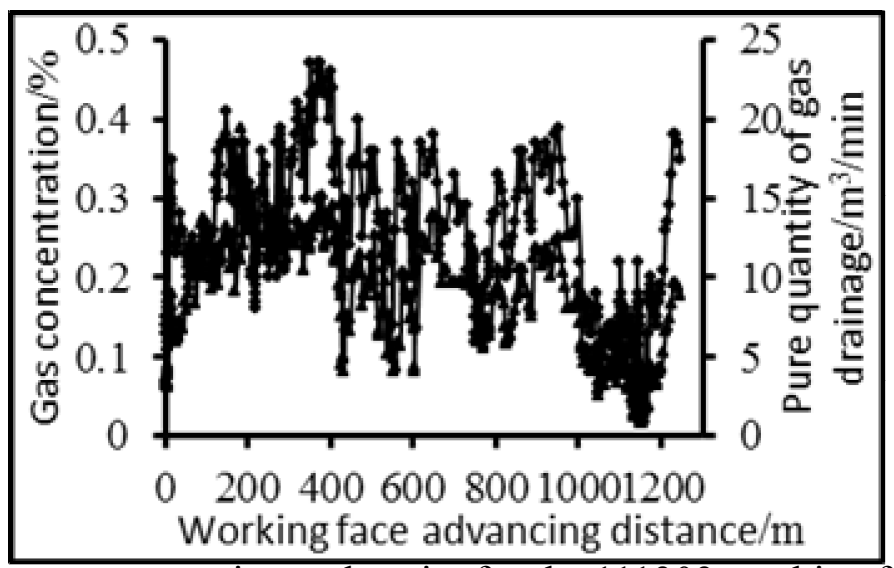

Figure.4 The curve of gas concentration and purity for the 111303 working face high pumping Lane bedding drilling

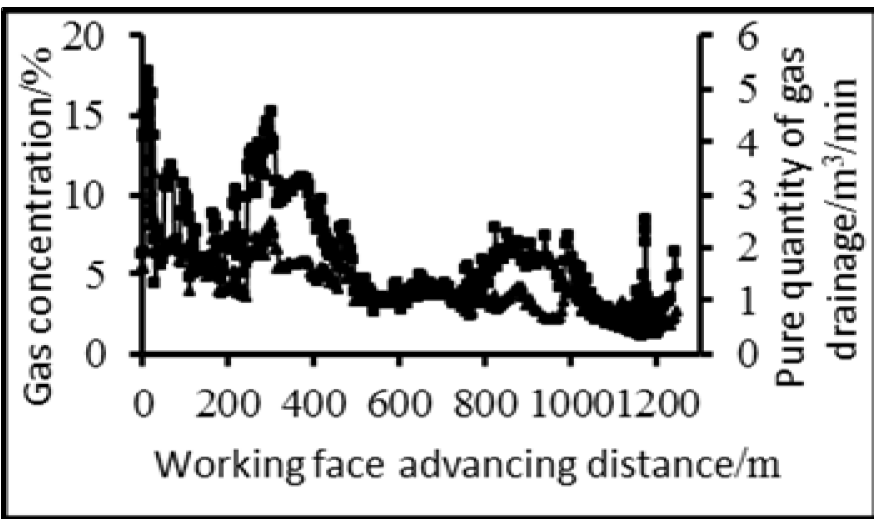

Figure. 5 The curve of gas concentration and purity for the 111303 working face Exhaust bedding drilling 
Table 1 statistical tables of working face

\begin{tabular}{cccc}
\hline $\begin{array}{c}\text { Pumping } \\
\text { arrange- } \\
\text { ment }\end{array}$ & $\begin{array}{c}\text { Pumping } \\
\text { capacity } \\
(\text { Million } \\
\left.\mathrm{m}^{3}\right)\end{array}$ & $\begin{array}{c}\text { Total } \\
\text { Pumping } \\
\text { quantity }\end{array}$ & $\begin{array}{c}\text { Total pumping } \\
\text { capacity }\end{array}$ \\
\hline $\begin{array}{c}\text { Bedding } \\
\text { drilling } \\
\text { drainage } \\
\text { Extrac- } \\
\text { tion of } \\
\text { high }\end{array}$ & 3.35 & $26.27 \%$ & $18.44 \%$ \\
pumping \\
Lane \\
$\begin{array}{c}\text { The wind } \\
\text { exhaust } \\
\text { gas }\end{array}$ & 9.41 & $73.73 \%$ & $51.78 \%$ \\
Total & 18.17 & - & \\
\hline
\end{tabular}

(2) Drilling of the bedding borehole is an important regional measure to prevent and control the coal gas dynamic disasters.

(3) After the initial pressure,the roof of working face and high pumping lane formed good fracture channel,the pumping volume gradually increased after the stability at the higher level, the results show that the design position of high pumping lane is reasonable, and can be pumped to the high concentration of gas, and the better results are obtained.

(4) High pumping lane in front of the pressure relief gas and behind the working face mining goaf gas accumulation drainage effect is good in normal mining period of working face. These effective intercept the goaf gas to accumulate at the upper corner angle, and prevent the gas from the working face, and make the air exhaust gas quantity decrease after good effect,and ensure the safety of the working face and rapid advance.The pumping of high pumping lane is an important type of discharge gas.

\section{Study on the effect of water injection in coal seam}

After the 111303 working meet the coal seam gas drainage standards,measures of deep hole static pressuring water injectionton prevent and control the impact of coal pressure on coal body with drilling boreholes ${ }^{[3]}$. Water injection hole and working face to promote the direction of vertical,the length of drilling hole is $1 / 3 \sim 1 / 2$. The hydrostatic pressure is $1 \sim 1.5 \mathrm{MPa}$ with small flow water injection processing, and the average flow rate of drilling is $0.82 \mathrm{~m}^{3} / \mathrm{h}$. The average flow rate of the drilling hole is kept in the range of $1.1 \sim 1.3 \mathrm{~m}^{3} / \mathrm{h}$, and the water injection time is maintained at about 10 days. The test shows that:

(1)The water injection volume of the drilling field in the working face machine roadway is $0.017 \sim 0.0301 \mathrm{~m}^{3} / \mathrm{t}$, and the average is $0.021 \mathrm{~m}^{3} / \mathrm{t}$. The increment of water content of the coal seam is $1.64 \% \sim 3.35 \%$, the average $2.19 \%$, which basically accords with the requirement not less than $2 \%$ of the water cut in the coal seam with the impact tendency.

(2)The water injection volume of the drilling field in The working face wind roadway is $0.014 \sim 0.031 \mathrm{~m}^{3} / \mathrm{t}$, and the average is $0.025 \mathrm{~m}^{3} / \mathrm{t}$. The increment of water content of the coal seam is $1.55 \% \sim 4.1 \%$, the average $2.69 \%$, which basically accords with the requirement not less than $2 \%$ of the water cut in the coal seam with the impact tendency.

\section{Verification analysis on working face outstanding risk}

In 111303 mining working face mining process, conduct Regional validation and prediction of working area in the non outburst dangerous area using the drilling bits index s, gas desorption index of drill cuttings (K1) and drilling cuttings grain size index.Forecast index see table 2. 
Table 2 Regional validation and maximum working surface prediction index in working face

\begin{tabular}{cccc}
\hline & $\begin{array}{c}\text { Drilling chip } \\
\text { quantity index } S \\
(\mathrm{~kg} / \mathrm{m})\end{array}$ & $\begin{array}{c}\text { Gas desorption index } \\
\text { of drill cuttings } K_{I} \\
(\mathrm{ml} / \mathrm{g} \bullet \min 0.5)\end{array}$ & $\begin{array}{c}\text { Granularity of the drilling } \\
\text { bits } \begin{array}{c}\text { the ratio of the drilling } \\
\text { bits in the } 3 \mathrm{~mm})\end{array}\end{array}$ \\
\hline $\begin{array}{c}\text { Maximum predic- } \\
\text { tive index }\end{array}$ & 3.2 & 0.07 & $28.1 \%$ \\
$\begin{array}{c}\text { Predictive index } \\
\text { critical value }\end{array}$ & 6 & 0.5 & $30 \%$ \\
\hline
\end{tabular}

From table 2, it can be known that there is no danger of using the S, the gas desorption index of $\mathrm{K} 1$, and the grain size of the chip,and there is no abnormal phenomenon in the process of drilling.

\section{Conclusion}

After the 111303 working face using composite regional measures of the "pre pumping gas pre pumping standard and the water injection to reduce the impact of the coal seam",coalbed methane content and the value of water content to meet the criteria for determining, and the regional measures of "pre pumping gas + deep hole water injection" are effective.At the same time, working face mining safety completed also proved "pre pumping gas and deep water injection" is the most effective prevention and control of coal gas dynamic disasters, the mine deep mining dynamic disaster (including coal and gas outburst, rock burst) governance have reference and guidance.

\section{References}

[1]Yang Zhao.Prediction and prevention technology of high stress rock burst in deep mining[D], Shandong University of Science and Technology,2010.( In Chinese)

[2]Qianting Hu. Coal mine gas drainage and gas disaster prevention[M], China University of Mining and Technology press,2007.( In Chinese)

[3]Zongxiang Li, Yishan Pan,Zhihui Zhang. Determine the layout and parameters of water injection hole in the rock burst coal seam[J],Journal of coal,2004.( In Chinese) 